\title{
Sucrose stabilization of Respiratory Syncytial Virus (RSV) during nebulization and experimental infection
}

Drew D Grosz, Albert van Geelen, Jack M Gallup, Shannon J Hostetter, Rachel J Derscheid and Mark R Ackermann*

\begin{abstract}
Background: Respiratory syncytial virus (RSV) is a common respiratory pathogen that can cause severe pneumonia. In vivo studies of RSV can be difficult due to variation in viral infection and disease severity in some animal models. Factors that may contribute to the variation are decreases in viral titer due to preparation and storage and method of virus administration. Nebulization is one method of RSV administration that provides even distribution of virus to all lung lobes; however, the exact quantity of the virus killed by nebulization is not defined. To test the hypothesis that sucrose enhances RSV stability and infectivity, a series of in vitro experiments were conducted with RSV strain Memphis 37 stored at varying concentrations $(0 \%, 3 \%, 5 \%, 8 \%, 10 \%, 15 \%$, and $20 \%$ ) of sucrose as a possible cryo- and nebulization protectant. The optimal in vitro concentration was then assessed in vivo in a lamb model.
\end{abstract}

Methods: Prior to titering the virus on HEp-2 cells, the various virus solutions were subjected to one freeze-thaw cycle and one nebulization cycle. Forty-eight hours after viral plating, infectious foci were detected and counted using immunofluorescent imaging. Titers were determined after freeze-thaw and after freeze-thaw followed by nebulization, then compared to the stock titers (before freezing) as well as to one another to determine the loss of infectivity. To further test this in vivo, lambs 2 to 3 -days-old were infected via nebulization with RSV using inoculate containing either $20 \%$ sucrose or no sucrose followed by assessments of infection severity.

Results: Nebulization of virus in $0 \%$ sucrose resulted in a 0.580 log reduction in infectivity while virus in $20 \%$ sucrose exhibited a 0.297 log reduction. In vivo studies demonstrated that $20 \%$ sucrose enhanced RSV lesions and antigen distribution.

Conclusions: The data suggests that both nebulization and freeze-thawing of RSV in the absence of sucrose cause unacceptable losses in viral infectivity and that sucrose acts as a RSV protectant in both regards.

Keywords: Respiratory Syncytial Virus, RSV, Nebulization, Sucrose

\section{Background}

Globally, respiratory syncytial virus (RSV) is estimated to cause 64 million cases of respiratory disease annually with the majority of cases occurring in children under the age of 5 and approximately 160,000 cases resulting in death [1-7]. In the United States, RSV is associated with an estimated $20-25 \%$ of pneumonia cases in children and $70 \%$ of bronchiolitis cases requiring hospitalization $[1,2]$. While much has been learned about the virus and disease pathogenesis, there are no fully effective vaccines

\footnotetext{
* Correspondence: mackerma@iastate.edu

Department of Veterinary Pathology, College of Veterinary Medicine, lowa State University, 1600 S. 16th Street, Ames, IA 50011-1250, USA
}

or therapeutic regimens [8,9]. Animal models and in vitro studies have been instrumental in advancing knowledge of RSV pathogenesis; however, comparison of methodologies of studies is lacking.

Nebulization has been used as a method of RSV inoculation in various experimental animal models $[10,11]$. Other routes of inoculation include intranasal, intraocular, and intratracheal administration, while fiber optic bronchoscopic deposition has also been used successfully as a means of viral inoculation to specific regions of the lung (11). While each method has its advantages and disadvantages, nebulization results in a uniform distribution of virus throughout all lung lobes; however the 
extent to which nebulization damages or disrupts RSV has not yet been explored.

Sucrose has been used to protect RSV and other viral samples during shipping, storage and with swabs of virus [12-14]. The goals of this study were to: 1) determine the effects of freeze-thawing and nebulization on RSV stability/infectivity using RSV inoculum containing different concentrations of sucrose in vitro cultured in HEp-2 cells and, 2) test the extent to which the addition of sucrose to nebulized RSV inoculum affects RSV disease severity in vivo in perinatal lambs infected with a human strain of RSV. Lambs provide a good model of neonatal RSV infection. Ovine lung has similar development, structure, and cellularity to those of human infants [11]. Also, lambs are susceptible to human strains of RSV and develop lesions similar to those in human infants [11,15-17].

\section{Methods}

\section{Experimental design of in vitro studies} Growing HEp-2 cells

HEp- 2 cells were grown on $75 \mathrm{~cm}^{2}$ and/or $300 \mathrm{~cm}^{2}$ tissue culture flasks with a vent screw cap $\left(\mathrm{TPP}^{\circ}\right)$ using $12 \mathrm{~mL}$ or $45 \mathrm{~mL}$ media, respectively, of Dulbecco's Modification of Eagle's Medium (DMEM) (Mediatech, Inc. Cat. No. 10-013-CV), 10\% fetal bovine serum (FBS) (Atlanta Biologicals Cat. No. S11550), $50 \mu \mathrm{g} / \mathrm{mL}$ of kanamycin sulfate (Invitrogen Cat. No. 11815-032), and incubated at $37^{\circ} \mathrm{C}$ at $5 \% \mathrm{CO}_{2}$ and $93 \%$ humidity. Cells were passaged 1:6 every $2-3$ days, depending on cell confluence. Twelve-well cell culture plates (Costar $\left.{ }^{\circ}\right)$ were seeded with HEp-2 cells at a concentration of $2-3 \times 10^{5}$ per well containing $6.5 \mathrm{~mL}$ of media. Cell concentration was determined prior to passaging by hemocytometer (Bright-Line ${ }^{\circ}$ ) to determine approximate cells per $\mathrm{mL}$. Cells were allowed to grow overnight prior to infectious focus assay.

\section{RSV M37 stock and sucrose}

RSV Memphis strain 37 (RSV M37) was frozen at varying sucrose concentrations $(0 \%, 3 \%, 5 \%, 8 \%, 10 \%, 15 \%$, and 20\%) to assess infectivity after cryo-storage and nebulization. HEp-2 cells were grown, as stated above, and infected with RSV M37. After $48 \mathrm{hrs}$, the virus was isolated from the cells after a freeze-thaw cycle $\left(\right.$ at $-80^{\circ} \mathrm{C}$ ) followed by centrifugation ( $2500 \mathrm{rpm}$ for $10 \mathrm{~min}$ ). $5 \mathrm{~mL}$ of the supernatant was then added to varying amounts of PBS (Sigma Cat. No. P3813-10PAK; $0.138 \mathrm{M} \mathrm{NaCl}$, $0.0027 \mathrm{M} \mathrm{KCl}, \mathrm{pH} 7.4 @ 25^{\circ} \mathrm{C}$ ), 0\% sucrose and 10\% FBS solution or PBS, $60 \%$ sucrose and $10 \%$ FBS solution to attain desired sucrose concentrations of $0 \%, 3 \%, 5 \%, 8 \%$, $10 \%, 15 \%$, and $20 \%$. The solution of $60 \%(\mathrm{w} / \mathrm{v})$ sucrose in PBS was made, supplemented with $10 \%$ FBS and filtered using a Nalgene filter flask and used to accomplish the various desired final tested concentrations of sucrose mentioned above. A $0.5 \mathrm{~mL}$ aliquot was taken from each sucrose concentration and stored in a separate tube; this was used to determine the stock and post freeze-thaw titers of the virus. After preparation, samples were frozen at $-80^{\circ} \mathrm{C}$ for about 3 weeks before use. Upon use, samples were thawed in a $37^{\circ} \mathrm{C}$ water bath just until ice disappeared.

\section{Infecting HEp-2 cells with RSV M37 for infectious focus assay}

Viral titers were assessed prior to freezing, after freezing, and following nebulization in a standard infectious focus assay. Collected condensates of nebulized vapors containing RSV M37 were used to infect HEp-2 cells. Vapors were collected using a nebulization apparatus coupled to a modified cold trap. The nebulization apparatus included: a nebulizer compressor unit, PARI nebulizer tubing, PARI Sprint $^{\mathrm{Tm}}$ nebulizer (PARI LC ${ }^{\mathrm{Tm}}$ ), T-port connector, rubber stopper \#3 (22 $\mathrm{mm}$ inside diameter), modified garden hose rubber washer (30 $\mathrm{mm}$ outer diameter and $22 \mathrm{~mm}$ inside diameter), and a $250 \mathrm{~mL}$ flask (PYREX $\left.{ }^{\circ}\right) .6 \mathrm{~mL}$ of RSV M37 inoculum containing the varying sucrose concentrations stated above, were individually loaded into the PARI Sprint ${ }^{\mathrm{TM}}$ nebulizer and nebulized in three 2-mL amounts over a 23- minute period. A new nebulizer was used for each sucrose concentration. The condensed nebulized vapors within the $250 \mathrm{~mL}$ flasks were then diluted in duplicate with media in serial dilution fashion from $10^{-1}$ to $10^{-5}$. HEp-2 cells at a confluency of $75-85 \%$ (minimum of $50 \%$ ) were used for the infectious focus assay. Prior to viral inoculation, the media within pre-seeded 12-well plates was discarded. $200 \mu \mathrm{L}$ of diluted condensed viral vapor was then transferred to designated HEp-2 cell wells and allowed to incubate for $1 \mathrm{hr}$ at $37^{\circ} \mathrm{C}$ to allow virus-tocell contact. After $1 \mathrm{hr}, 1 \mathrm{~mL}$ of media was added to each well and the plates were again incubated at $37^{\circ} \mathrm{C}$ for $48 \mathrm{hrs}$ to allow for viral replication. Prior to freezing and post freezing, stock samples were also titered without the nebulization process; samples which came from aliquots of the original virus/sucrose preparations. Titers of these original pre-frozen viral stocks (with and without sucrose) ranged from $1.63 \times 10^{6}$ to $2.91 \times 10^{6} \mathrm{FFU} / \mathrm{mL}$. Multiplicity of infection (MOI) for each study was generally between 0.5 and 1 . All nebulization and plating was performed in a class II biosafety cabinet (NUAIRE ${ }^{\circ}$ ).

\section{Determining RSV M37 infected cells}

Immunofluorescence microscopy was used to determine cell infectivity. After the 48-hr incubation period, media within the wells was discarded and wells were rinsed once with TBStw [TBS-0.05\% Tween 20, pH 7.4 (TBStw)]. Cells were then fixed with $0.5 \mathrm{~mL} 60 \%$ acetone $/ 40 \%$ methanol solution for $1 \mathrm{~min}$. The fixative was then removed and plates were allowed to dry for $2 \mathrm{~min}$. Cells 
were rehydrated with $0.5 \mathrm{~mL}$ per well with TBStw and placed on a rotator (Boekel Scientific, model $260300 \mathrm{~F}$ ) for $1 \mathrm{~min}$ after which well contents were discarded. A $1 \mathrm{~mL}$ blocking solution containing 3\% bovine serum albumin (BSA) (Fisher Scientific, Hanover, IL) in TBStw was added to each well and plates were placed on the rotator for a minimum of $30 \mathrm{~min}$, after which well contents were discarded. $325 \mu \mathrm{L}$ of primary antibody [Meridian, MAb to RSV Fusion Protein, Cat. No. C87610M, Clone: RSV 3216 (B016)] containing 3\% BSA-TBStw at 1:800 dilution was added to each well and plates were incubated overnight at $4^{\circ} \mathrm{C}$ on a rocker apparatus, after which well contents were discarded and wells were rinsed with TBStw. $325 \mu \mathrm{L}$ of the secondary antibody (Invitrogen, Goat anti-Mouse Fab' conjugated to AlexaFluor 488, Cat. No. A11017) containing 3\% BSA-TBStw at 1:800 dilution was then added to each well and plates were placed on the rotator for a minimum of $30 \mathrm{~min}$, after which well contents were discarded. Wells were then rinsed twice with $1 \mathrm{~mL}$ TBStw. $1 \mathrm{~mL}$ TBStw was then added to each well and fluorescing foci were visualized using an Olympus CKX41 inverted microscope with an external florescence bulb; X-Cite series $120 \mathrm{Q}$ (Lumen Dynamics ${ }^{\circ}$ ). Cell aggregates $\geq 5$ cells were counted as one infectious focus. Infectious foci per well were then converted to focus forming units (FFU) per $\mathrm{mL}$ using the following formula: [(arithmetic mean $x$ dilution $\times 1000 \mu \mathrm{L} / \mathrm{mL}) / 200 \mu \mathrm{L}$ assessed $=\mathrm{FFU} / \mathrm{mL}]$. Images were taken using an Olympus DP20 cameramicroscope attachment.

\section{Experimental design of in vivo studies}

Three groups of 2 to 3-day-old lambs (either sex; Polypay, Suffolk, Dorsett cross breed) were used for the study. RSV strain (Memphis 37) was grown in HEp-2 cells and delivered $\left(1.25 \times 10^{6} \mathrm{FFU} / \mathrm{mL}\right)$ to lambs in $6 \mathrm{~mL}$ culture medium using a PARI Sprint ${ }^{\mathrm{Tm}}$ nebulizer (fitted with a cone-shaped face mask fitted with a rubber diaphragm that provided a seal around the mandible and nose) in three 2-mL increments over a 23 minute period. One group ( $\mathrm{n}=6$ lambs) received this amount of RSV in culture media containing $20 \%$ sucrose whereas another group ( $\mathrm{n}=6$ lambs) received this same amount of RSV in media lacking sucrose; control lambs $(n=2)$ received $6 \mathrm{~mL}$ culture medium (lacking virus) with $20 \%$ sucrose, also by nebulization. After inoculation with RSV, lambs in all groups received a daily antibiotic (Ceftiofur, 1$2 \mathrm{mg} / \mathrm{kg}$ body weight, intramuscular) to prevent secondary bacterial infections. Lamb temperatures, body weights, respiratory and heart rates were measured daily. Clinical severity of RSV disease for each lamb was assessed and scored as previously described $[11,17,18]$. Lambs were euthanized by sodium pentobarbital overdose on day 6 post-inoculation (p.i.) when RSV-induced lesions are maximal in this model $[11,17,18]$. Throughout the experiment, lambs received a custom diet (Milk Products Inc., Chilton, WI, USA) that lacked supplemental iodide, and the lack of iodide was verified using anion-exchange chromatography. The purpose of eliminating dietary iodide was to avoid any potential production of hypoiodite $\left(\mathrm{OI}^{-}\right)$which is a hypohalide generated by the ovine oxidative mucosal Duox/LPO/halide defense system in the presence of sufficient iodide. Hypoiodite has been demonstrated to be destructive to RSV [19]. All animal experiments were approved by the Institutional Animal Care and Use Committee (IACUC) of Iowa State University.

\section{Post-mortem analysis of RSV disease severity}

After euthanasia, the thorax was opened, lungs were removed, gross lesions scored as described previously $[11,17,18]$ and photographed in situ and ex vivo. Tissue samples were collected from all lung lobes of each animal in a standardized manner. Multiple samples from each lobe were placed into cryovials and snap-frozen in liquid nitrogen for subsequent use in RNA isolation for hydrolysis probe-based reverse transcription real-time quantitative polymerase chain reaction (RT-qPCR). Two samples from each lobe were placed into tissue cassettes and fixed in 10\% neutral-buffered formalin (NBF) for histological and immunohistochemical analysis, and two lung samples from each animal were placed into cryomolds and covered with CRYO-OCT Compound (Tissue-Tek, Torrance, CA) then stored at $-80^{\circ} \mathrm{C}$ until cryosectioning. Immediately after lung removal, percentage parenchymal involvement was estimated for each lobe. Group averages were calculated to obtain the gross lesion score for each lobe $[17,18]$.

In addition to the lung samples collected for RNA isolation and histological samples, bronchoalveolar lavage fluid (BALF) was collected from each lamb for determination of viral titers and cytology. BALF for viral titer assessment was obtained by flushing the right caudal lung lobe through a major bronchus with $5 \mathrm{~mL}$ of ice-cold modified Iscove's media (42.5\% Iscove's modified Dulbecco's medium, $7.5 \%$ glycerol, $1 \%$ heat-inactivated FBS, $49 \%$ DMEM, and $5 \mu \mathrm{g} / \mathrm{mL}$ kanamycin sulfate). $1 \mathrm{~mL}$ of each recovered BALF sample was then used immediately (never being frozen) for infectious focus assay. BALF for cytology ( 0.5 mL from each lamb) was obtained by flushing a major bronchus of the accessory lobe with $1 \mathrm{~mL}$ PBS, pH 7.4. These BALF samples were submitted to the clinical pathology laboratory (Iowa State University, College of Veterinary Medicine) for total nucleated cell counts and slide preparation for cytology. An ADVIA120 $0^{\text {ta }}$ automated hematology analyzer was used to perform cell counts. Cytospin preparations of BALF were performed using a Shandon Cytospin 3 set at $800 \mathrm{rpm}$ (samples were spun for 10 minutes with low acceleration). Slides were stained with modified Wright's 
using a Hematek automated staining system. Differential cell counts (based on a 300 cell differential) were performed by a board-certified veterinary clinical pathologist blind to the identity of the samples.

Histologic scores were determined by evaluating percent consolidation and converting the observed percentage ranges to a simple integer based on a consolidation scale used by our laboratory previously $(35,36): 0 \%$ consolidation $=0,1-9 \%$ consolidation $=1,10-39 \%$ consolidation $=2,40-69 \%$ consolidation $=3,70-100 \%$ consolidation $=$ $4[17,18]$. Group averages were calculated to obtain the alveolar consolidation score.

\section{$R N A$ isolation and $R T-q P C R$}

Tissues from right and left cranial, right and left middle, and right and left caudal lung lobes (0.3-0.4 g of each) were homogenized in TRIzol (Invitrogen), pooled in equal $(\mathrm{w} / \mathrm{v})$ portions to create representative slurries for each animal, each of which was adjusted to $0.091 \mathrm{~g} / \mathrm{mL}$ with additional TRIzol. Total RNA isolation continued as per manufacturer's guidelines (Invitrogen) followed by DNase treatment (Ambion, TURBO DNase, Austin, TX) and diluting the isolates 1:10 with a combination of RNaseOUT (Invitrogen) and nuclease-free water (Ambion/ Invitrogen). A NanoDrop (Thermo Fisher Scientific) was used to assess each sample for general RNA purity and quantity $\left(\mathrm{A}_{260 \mathrm{~nm}} / \mathrm{A}_{280 \mathrm{~nm}}\right.$ all $\left.>1.98\right)$. In addition, Agilent Bioanalyzer 2100 analysis of the RNA routinely showed RIN values >8.0. RT-qPCR was carried out using OneStep Fast qRT-PCR Kit mastermix (Quanta, BioScience, Gaithersburg, MD) in a GeneAmp 5700 Sequence Detection System (Applied Biosystems, Carlsbad, CA) employing PREXCEL-Q for all set-up calculations [20-23]. Primers and probe for the RSV M37 nucleoprotein mRNA sequence targeted by the RT-qPCR in this study were designed using ABI Primer Express 2.0 based on RSV accession number M74568. Forward primer: 5'-GCTCTTAG CAAAGTCAAGTTGAACGA; reverse primer: 5'-TGCTC CGTTGGATGGTGTATT; hydrolysis probe: 5'-6FAMACACTCAACAAAGATCAACTTCTGTCATCCAGC-TA MRA. Prior to RT-qPCR, each 1:10-diluted total RNA sample was further diluted so that each final reaction contained $0.784 \mathrm{ng}$ total RNA/ $\mu \mathrm{L}$; a dilution and sample concentration determined to be optimal by PREXCEL-Q $[19,20]$. The GeneAmp 5700 Sequence Detection System thermocycling conditions were 5 minutes at $50^{\circ} \mathrm{C} ; 30 \mathrm{sec}-$ onds at $95^{\circ} \mathrm{C}$; and 45 cycles of: 3 seconds at $95^{\circ} \mathrm{C}$ and 30 seconds at $60^{\circ} \mathrm{C}$. Samples and standards were assessed in duplicate wells and each quantification cycle (Cq) was converted to a relative quantity $\left(X_{0} r\right)$ based on a relative dilution standard curve using the equation: Xor = $\mathrm{E}_{\mathrm{AMP}}{ }^{(\mathrm{b}-\mathrm{Cq})}$, where $\mathrm{E}_{\mathrm{AMP}}$ and $\mathrm{b}$ are the exponential PCR amplification efficiency and the $y$-intercept values, respectively, obtained from a sample mixture-derived standard curve for RSV M37 nucleoprotein. The efficiencycorrected delta $\mathrm{Cq}\left(\mathrm{E}_{\mathrm{AMP}}{ }^{\mathrm{\Delta Cq}}\right)$ method was employed for final quantification calculations. Results were normalized to total tissue RNA loaded per reaction; identical for all reactions as per the PREXCEL-Q protocol. No-RT control reactions all proved negative for RSV and the assays were determined to be free of inhibition based on the PREXCEL-Q method [20-23].

\section{Immunohistochemistry for RSV}

Immunohistochemistry for localization, and relative quantification of RSV antigen was performed on formalin-fixed paraffin-embedded (FFPE) tissues $[11,17,18]$. After heating for 15 minutes at $58^{\circ} \mathrm{C}$ and standard deparaffinization through xylene and graded alcohols, antigen retrieval was performed using TE-0.05\% Tween 20, pH 9.0 and a Decloaking Chamber ${ }^{\text {ma }}$ Plus (Biocare Medical, Concord, CA). A temperature of $125^{\circ} \mathrm{C}$ was reached in about $18 \mathrm{mi}-$ nutes, after which the system cooled to $80^{\circ} \mathrm{C}$ after another 22 minutes. Blocking for 15 minutes with 3\% bovine serum albumin (BSA) (Fisher Scientific, Hanover, IL) in TBS-0.05\% Tween 20, pH 7.4 (TBStw) and blocking with $20 \%$ normal swine serum (NSS) (Gibco/Invitrogen) in TBStw for 15 minutes was followed by addition of a primary polyclonal goat anti-RSV (all antigens) antibody (EMD/Millipore/Chemicon, Billerica, MA) which was applied for 1.5 hours at room temperature $\left(\sim 22^{\circ} \mathrm{C}\right)$ at a dilution of 1:500 $(8-10 \mu \mathrm{g} / \mathrm{mL})$ in TBStw containing $10 \%$ NSS and 3\% BSA. After TBStw rinses, biotinylated rabbit anti-goat secondary antibody (Kirkegaard-Perry Labs, Gaithersburg, MD) diluted 1:300 in TBStw containing $10 \%$ NSS and 3\% BSA was applied for 45 minutes. Slides were rinsed, blocked for endogenous peroxidase activity (using 3\% peroxide in TBStw) for 25 minutes, and streptavidin-conjugated HRP (Invitrogen) diluted 1:200 in TBStw was applied for 30 minutes. After rinsing slides with TBStw, Nova Red (Vector, Burlingame, CA) was applied for about 90 seconds followed by water rinses, counterstaining in Harris' hematoxylin for 2 minutes, bluing with alkaline Scott's water for 1 minute, standard dehydration through graded alcohols and xylene, and coverslipping using Permount (Sigma, St. Louis, MO). Slides (containing two pieces of lung tissue each) were scored using the following procedure: 20 unique 10X fields on each slide were assessed for antigen staining and immunoreactive cells were counted within bronchioles and alveoli. The number of cells immunoreactive for RSV per field was then scored as percent lobular involvement based on the method used in our previous studies $[17,18]$ without using the non-parametric 1-4 scale assignment.

\section{Statistical analysis}

All analyses were performed using GraphPad Prism 6 (GraphPad Software Inc, La Jolla, CA). RT-qPCR, IHC 
and gross lesion data was assessed by one-way ANOVA followed by Tukey's post-test. All clinical data were assessed by two-way ANOVA, and cumulative weight change was additionally assessed by one-way ANOVA followed by Tukey's post-test. Scored parameters were assessed using non-parametric (Kruskal-Wallis) and/or unpaired, two-tailed, non-parametric Mann-Whitney test analyses. Significance was accepted at $P<0.1$ in these evaluations.

\section{Results}

\section{In-vitro studies}

RSV in $0 \%$ sucrose concentration showed a 0.256 log drop $(44.52 \%$ loss) in infectivity due to freeze-thawing and a $0.580 \log$ drop ( $73.70 \%$ loss) due to nebulization; indicating an overall log drop of 0.836 (85.41\% loss in infectivity) (Figure 1). RSV in $3 \%$ sucrose concentration showed no log drop ( $0.00 \%$ loss $)$ due to freeze-thawing and a $0.831 \log$ drop (85.25\% loss) due to nebulization representing an overall log drop of 0.694 (79.75\% loss) (Figure 1). RSV in 5\% sucrose concentration showed a $0.198 \log$ drop $(36.61 \%$ loss $)$ due to freeze-thawing and a 0.589 log drop (74.24\% loss) due to nebulization yielding an overall log drop of 0.787 (83.67\% loss) (Figure 1). RSV in $8 \%$ sucrose concentration showed no log drop $(0.00 \%$ loss $)$ due to freeze-thawing and a 0.477 log drop (66.67\% loss) due to nebulization suggesting an overall log drop of 0.448 (64.38\% loss) (Figure 1). RSV in $10 \%$ sucrose concentration showed no log drop ( $0.00 \%$ loss) due to freeze-thawing and a $0.461 \log$ drop (65.39\% loss) due to nebulization signifying an overall log drop of 0.362 (56.58\% loss) (Figure 1). RSV in 15\% sucrose concentration showed no log drop $(0.00 \%$ loss $)$ due to freeze-thawing and a $0.398 \log$ drop $(60.00 \%$ loss $)$ due to nebulization indicating an overall log drop of 0.263 (45.46\% loss) (Figure 1). RSV in 20\% sucrose concentration showed no log drop $(0.00 \%$ loss $)$ due to freezethawing and a 0.297 log drop (49.55\% loss) due to nebulization demonstrating an overall log drop of 0.266 (45.75\% loss) (Figure 1).

\section{In-vivo studies}

Clinically, there were no significant differences in expiratory effort, weight gain, temperature, heart or respiratory rates. There was a nearly-significant trend of increased gross lesion scores $(11 \pm 5.9)$ for lambs receiving RSV in $20 \%$ sucrose compared to lambs lacking sucrose $(5.7 \pm$ $0.95)$ (Figure 2) and consolidation scores of histopathologic lesions were significantly $(P<0.1)$ higher in lambs receiving RSV in $20 \%$ sucrose $(1.6 \pm 0.2$ estimated number) compared to lambs receiving RSV lacking sucrose (1.2 \pm 0.14 estimated number) (Figure 3$)$. Also, histologically, neutrophil infiltration into infected bronchioles was significantly increased $(P<0.1)$ in lambs receiving RSV in $20 \%$ sucrose $(0.9 \pm 0.14$ estimated number $)$ compared to lambs receiving RSV without sucrose $(0.6 \pm 0.1$ estimated number) (Figure 4). To evaluate the effect of RSV in $20 \%$ sucrose on inflammatory cell populations within the lung, differential cell counts were performed on BALF and significant differences in monocytes, lymphocytes, and neutrophils were not observed.

RSV viral titers from BALF fluid and RSV mRNA levels in lung trended higher in lambs receiving RSV in $20 \%$ sucrose compared to lambs receiving RSV lacking sucrose; controls lacked RSV viral titer and viral mRNA (Figure 2). RSV viral antigen detected by immunohistochemistry was significantly increased $(P<0.05)$ for antigen levels in bronchioles of lambs receiving RSV in $20 \%$

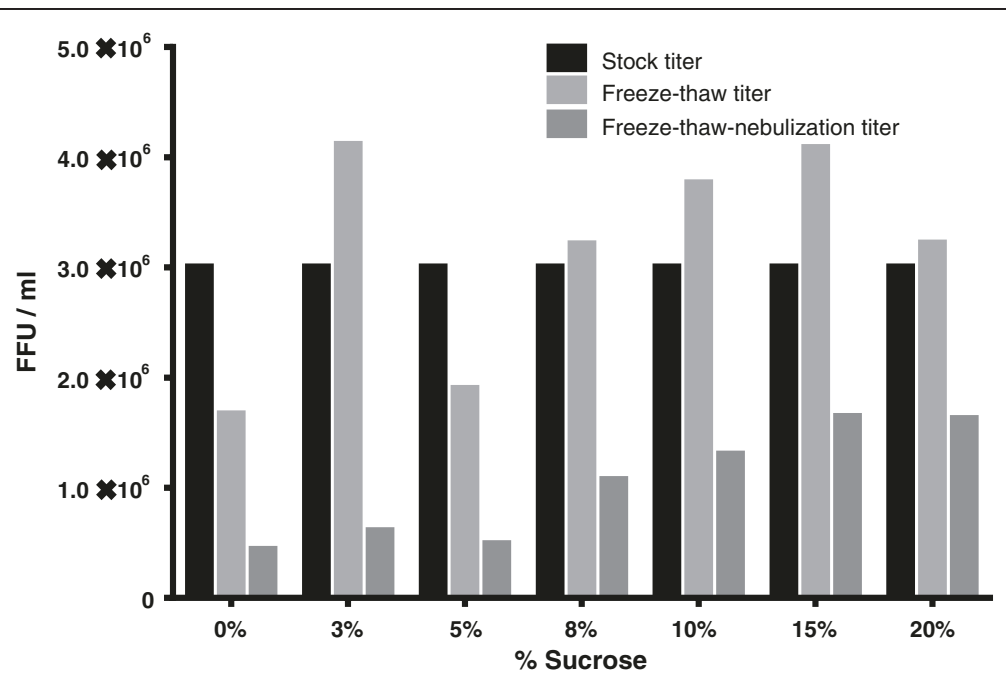

Figure 1 Titer trends of M37 stock and M37 + sucrose solutions after freeze-thawing and freeze-thawing followed by nebulization. All values have been factor-adjusted to a stock titer of $3 \times 10^{6}$. 


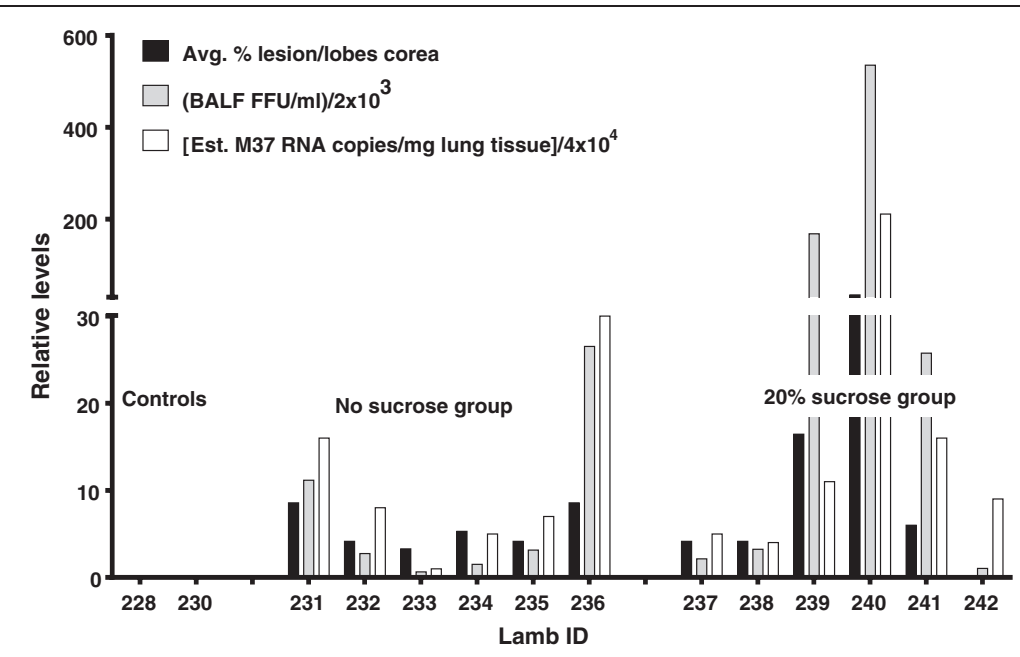

Figure 2 Gross lesion score, BAL titer of RSV and RNA levels of RSV detected in lung of lambs inoculated with RSV with and without sucrose.

sucrose $(17 \pm 2.1)$ compared to antigen in bronchioles of lambs receiving RSV without sucrose (5 \pm 0.9 ) (Figure 5). Also, RSV viral antigen scoring was significantly increased in alveolar epithelium $(P<0.001)$ in lungs of lambs receiving RSV in $20 \%$ sucrose $(35 \pm 7.3)$ compared to lambs receiving RSV without sucrose $(8.4 \pm 1.9)$ (Figure 5 ).

\section{Discussion}

The use of sucrose to preserve and enhance infectivity/ virulence and to transport respiratory syncytial virus (RSV) has been assessed previously but not, to our knowledge, with nebulization. We suspected that there could be a balance/give-and-take between the extent to which sucrose stabilization may protect RSV from damage by freeze-thaw, affect the virulence of the virus in vivo and in vitro and mitigate potential effects of the nebulization process itself. In 1968 it was shown that $44.5 \%$ sucrose was optimal for RSV storage at $-70^{\circ} \mathrm{C}$ and that this concentration of sucrose in cotton swabs retained RSV viability for up to 7 days [12]. Another study has shown that $0.2 \mathrm{M}$ sucrose phosphate resulted in significantly higher recovery of RSV as well as other viruses (cytomegalovirus, varicella-zoster virus, herpes simplex virus type 1) compared to $70 \%$ sorbitol [13]. Neither of these studies assessed nebulization nor did they assess animal infection with recovered virus.

In this study, the addition of sucrose to RSV M37 affected survival of virus during freeze-thawing, freeze-

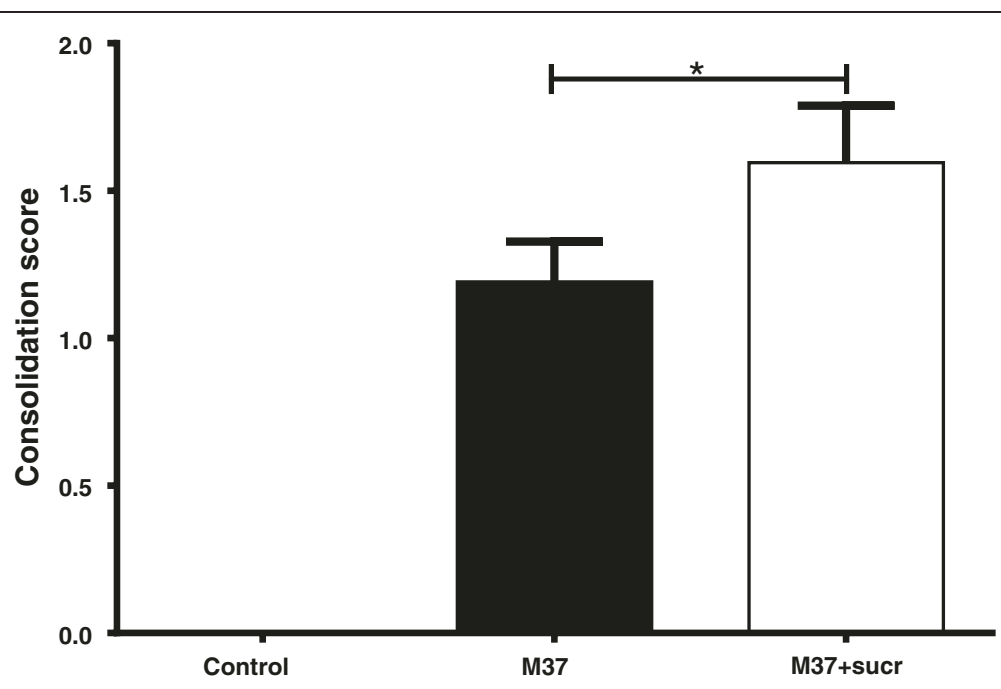

Figure 3 Consolidation scores (histopathologic lesions) of lungs of lambs inoculated with RSV with and without sucrose by nebulization. Lesions are significantly increased in lung of lambs inoculated with RSV containing sucrose compared to lambs receiving RSV lacking sucrose. Control lambs lacked lesions. Control $n=2 ; M 37 n=6 ; M 37+$ sucr $n=6$. Error bars represent $S E M,{ }^{*} P<0.1$. 


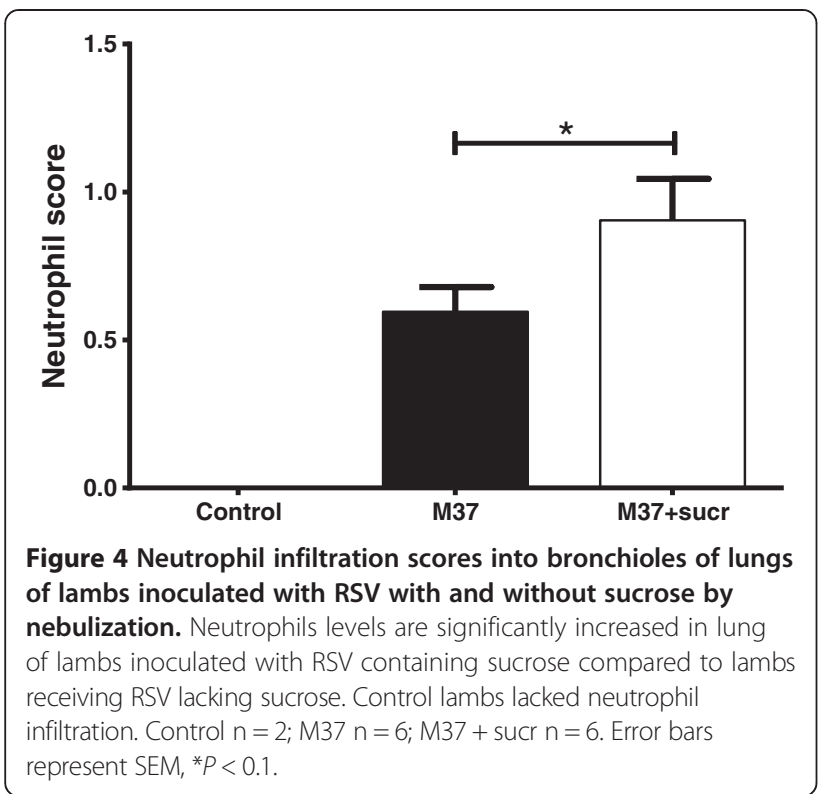

thawing followed by nebulization, and the extent of virulence in vivo. With freeze-thaw titers, there is an increase in RSV titer (virus survival) with the addition of sucrose concentrations compared to $0 \%$ (no) sucrose. The variability in stock and freeze-thawing titers resulted in some concentrations with freeze-thawing titers higher than stock; however, these were not statistically significant differences and we speculate that this might be caused by the breaking up of viral aggregates during the freeze-thaw process; thereby freeing up more infective virions prior to titering by infectious focus assay. The mechanism(s) by which sucrose may reduce viral loss with freeze-thaw could not be determined and was not further assessed in this study. For nebulization, a preservation of titer (e.g., increased RSV viability) occurred with higher sucrose concentrations compared to lower/ no sucrose concentrations. Furthermore, even though RSV in 15 and 20\% sucrose concentrations exhibited limited viral titer loss, some loss did occur at these concentrations. Given the nearly-significant trends in the titer data, sucrose seems to play a key role in RSV protection against the deleterious effects of both freezethawing and freeze-thawing followed by nebulization.

The delivery of RSV in sucrose to lamb lung by nebulization also had an effect on virulence in vivo as reflected by significantly increased consolidation scores (histopathologic lesions), neutrophil infiltration into bronchioles, and antigen levels (IHC scores). The reason(s) for the increased virulence is likely due, at least in part, to the increased survival of RSV throughout freeze-thawing and the freeze-thawing-nebulization process on account of the protective effect(s) of sucrose. Such increased preservation of viable virions would effectively increase the amount of infective virus deposited onto the respiratory mucosa. Although it is also possible that sucrose enhances attachment or maintains virus survival within the air-surface liquid (ASL) and/or positively affects some other aspects of RSV virulence, exploring such possibilities was not within the scope of this study. Sucrose may also affect droplet size and aggregation of viral particles which could alter the amount of virus per droplet and affect infectivity. Reasonable considerations for the positive effects on RSV stability include osmotic activity of sucrose in preserving the viral envelope, charge interactions between sucrose and the envelope, and bridging by sucrose of other protective media components to the viral envelope.

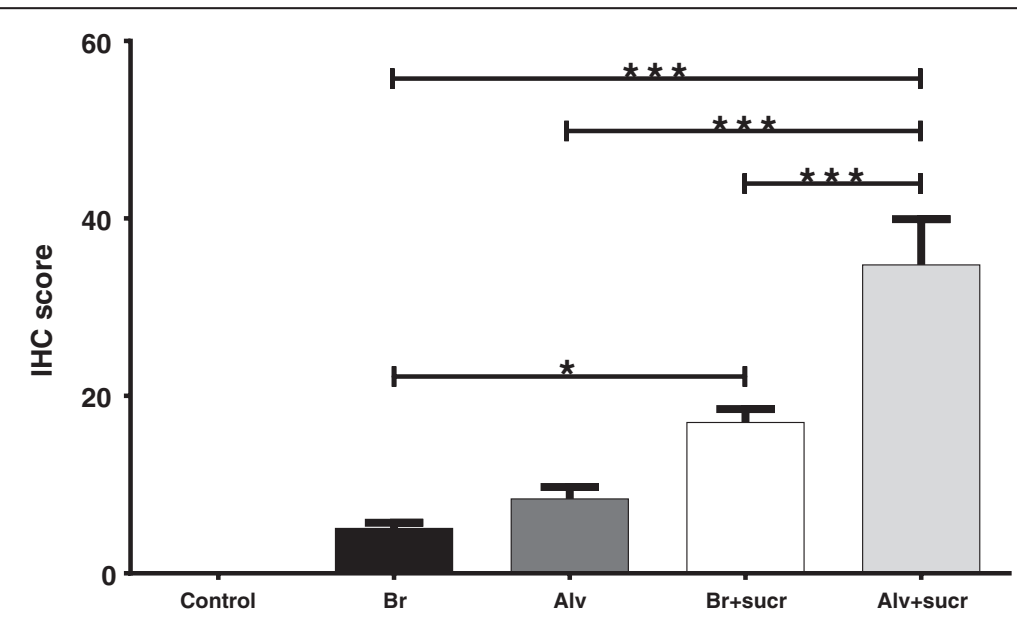

Figure 5 RSV antigen levels in lungs of lambs inoculated with RSV with and without sucrose by nebulization. RSV viral antigen levels are significantly increased in both bronchioles (Br) and alveolar (Alv) epithelium of lung of lambs inoculated with RSV containing 20\% sucrose compared to lambs receiving RSV lacking sucrose. Control lambs lacked RSV antigen. Control $n=14 ; \mathrm{Br} n=42 ; \mathrm{Alv} n=42 ; \mathrm{Br}+\operatorname{sucr} n=39 ; \mathrm{Alv}+$ sucr $n=39$. Error bars represent $S E M,{ }^{*} P<0.05,{ }^{* *} P<0.001$. 
Although the addition of sucrose resulted in trends of increased gross lesions, RSV mRNA levels and BAL titers in infected lambs, these differences were not significant. This may be due to the timepoint post-infection (six days) at which lesions are maximal; however, it is possible that viral replication peaks at days 3-5 in lambs, as it does in certain other models $[11,12,17,18]$. Thus, it is possible that sucrose may have a significant effect on gross lesions, RNA levels and viral titers but perhaps earlier than the six-day timepoint post-nebulization. Because of the significance on some parameters and trends of enhanced infectivity in others, sucrose addition appears to be beneficial in preserving virulence in such studies.

\section{Conclusions}

This study provides important information on methodology of in vitro and in vivo studies with a human strain of RSV and highlights the importance of carrying out proof-of-concept studies. This is especially true for studies in lambs which are out-bred animals and which are large enough to necessitate the use of larger volumes of virus. Optimizing virus stability and ensuring consistency in viral delivery are vital. While the nebulization method is effective in the lamb and other experimental animal models, these findings will also assist in comparison between studies in models that use different modes of inoculation.

\section{Abbreviations \\ RSV: Respiratory syncytial virus; RSV M37: Respiratory syncytial virus Memphis strain 37; DMEM: Dulbecco's Modification of Eagle's Medium; \\ BALF: Bronchoalveolar lavage fluid; Sucr: Sucrose; FBS: Fetal bovine serum; BSA: Bovine serum albumin; TBS: TRIS-buffered saline; TBStw: TRIS-buffered saline + 0.05\% tween 20; FFU: Focus forming units; IACUC: Institutional Animal Care and Use Committee; RT-qPCR: Reverse transcription quantitative polymerase chain reaction; NBF: Neutral-buffered formalin; Cq: Quantification cycle; $X_{0}$ r: Relative quantity; FFPE: Formalin-fixed paraffin-embedded; ANOVA: Analysis of variance; Br: Bronchiolar; Alv: Alveolar; \\ IHC: Immunohistochemistry; SEM: Standard error of the mean.}

\section{Competing interests}

The authors declare that they have no competing interests.

\section{Authors' contributions}

DG completed the nebulization studies in vitro, AvG worked with DG on the in vitro studies and completed virology for both in vitro and in vivo studies, JG assisted with all studies and completed the IHC and RT-qPCR assays and graphing, SH completed the cytology assays, RD assisted with the design and animal studies and MA developed experimental designs, assisted with in vitro studies and much of the in vivo studies and completed the histopathology and immunohistochemistry assessments. All contributed to the assessment of the data and manuscript preparation. All authors read and approved the final manuscript.

\section{Acknowledgements \\ Funding for the project was provided by NIH NIAID R56AI09100 and ISU CVM NIH 2 T35 OD012199.}

Received: 19 July 2013 Accepted: 12 March 2014

Published: 18 March 2014

\section{References}

1. Nair H, Nokes DJ, Gessner BD, Dherani M, Madhi SA, Singleton RJ, O'Brien KL, Roca A, Wright PF, Bruce N, Chandran A, Theodoratou E, Sutanto A, Sedyaningsih ER, Ngama M, Munywoki PK, Kartasasmita C, Simões AF, Rudan I, Weber MW, Campbell H: Global burden of acute lower respiratory infections due to respiratory syncytial virus in young children: A systematic review and meta-analysis. Lancet 2010, 375:1545-1555.

2. WHO: Acute respiratory infections (update September 2009). 2009 09/09 [cited 2013]. http://www.who.int/vaccine_research/diseases/ari/en/index2.html.

3. Collins PL, Melero JA: Progress in understanding and controlling respiratory syncytial virus: still crazy after all these years. Virus Res 2011, 162:80-99.

4. Garcia CG, Bhore R, Soriano-Fallas A, Trost M, Chason R, Ramilo O, Mejias A Risk factors in children hospitalized with RSV bronchiolitis versus nonRSV bronchiolitis. Pediatrics 2010, 126:e1453-e1460.

5. Hon KL, Leung TF, Cheng WY, Ko NM, Tang WK, Wong WW, Yeung WH, Chan PK: Respiratory syncytial virus morbidity, premorbid factors, seasonality, and implications for prophylaxis. J Crit Care 2012, 5:464-468.

6. Sommer C, Resch B, Simoes EA: Risk factors for severe respiratory syncytial virus lower respiratory tract infection. J Open Microbiol 2012, 5:144-154.

7. Welliver RC, Checchia PA, Bauman JH, Fernandes AW, Mahadevia PJ, Hall CB: Fatality rates in published reports of RSV hospitalizations among highrisk and otherwise healthy children. Curr Med Res Opin 2010, 26:2175-2181

8. Abed Y, Boivin G: Treatment of respiratory virus infections. Antiviral Res 2006, 70:1-16

9. Empey KM, Peebles RS Jr, Kolls JK: Pharmacologic advances in the treatment and prevention of respiratory syncytial virus. Clin Infect Dis 2010, 50:1258-1267.

10. Bem RA, Domachowske JB, Rosenberg HF: Animal models of human respiratory syncytial virus disease. Am J Physiol Lung Cell Mol Physiol 2011, 301:L148-L156.

11. Derscheid RJ, Ackermann MR: Perinatal lamb model of respiratory syncytial virus (RSV) infection. Viruses 2012, 4:2359-2378.

12. Law TJ, Hull RN: The stabilizing effect of sucrose upon respiratory syncytial virus infectivity. Proc Soc Exp Biol Med 1968, 128:515-518.

13. Howell $\mathrm{CL}$, Miller MJ: Effect of sucrose phosphate and sorbitol on infectivity of enveloped viruses during storage. J Clin Microbiol 1983, 18:658-662.

14. Gupta CK, Leszczynski J, Gupta RK, Siber GR: Stabilization of respiratory syncytial virus (RSV) against thermal inactivation and freeze-thaw cycles for development and control of RSV vaccines and immune globulin. Vaccine 1996, 15:1417-1420.

15. Sow FB, Gallup JM, Krishnan S, Patera AC, Suzich J, Ackermann MR: Respiratory syncytial virus infection is associated with an altered innate immunity and a heightened pro-inflammatory response in the lungs of preterm lambs. Respir Res 2011, 12(1):106.

16. Sow FB, Gallup JM, Olivier A, Krishnan S, Patera AC, Suzich J, Ackermann MR: Respiratory syncytial virus is associated with an inflammatory response in lungs and architectural remodeling of lung-draining lymph nodes of newborn lambs. Am J Physiol Lung Cell Mol Physiol 2011, 300:L12-L24

17. Olivier A, Gallup JM, de Macedo MM, Varga SM, Ackermann MR: Human respiratory syncytial virus $A 2$ strain replicates and induces innate immune responses by respiratory epithelia of neonatal lambs. Int J Exp Pathol 2009, 90:431-438.

18. Olivier A, Gallup JM, van Geelen A, Ackermann MR: Exogenous administration of vascular endothelial growth factor prior to human respiratory syncytial virus $A 2$ infection reduces pulmonary pathology in neonatal lambs and alters epithelial innate immune responses. Exp Lung Res 2011, 37:131-143.

19. Fischer AJ, Lennemann NJ, Krishnamurthy S, Pocza P, Durairaj L, Launspack $J$, Rhein BA, Wohlford-Lenane C, Lorentzen D, Banfi B, McCray PB Jr: Enhancement of respiratory mucosal antiviral defenses by the oxidation of iodide. Am J Respir Cell Mol Biol 2011, 45:874-881.

20. Gallup JM, Ackermann MR: Addressing fluorogenic real-time $\mathrm{PPCR}$ inhibition using the novel custom Excel file system 'FocusField26GallupqPCRSet-upTool-001' to attain consistently high fidelity qPCR reactions. Biol Proced Online 2006, 8(1):87-155. PMCID: 1592462. 
21. Gallup JM, Ackermann MR: The 'PREXCEL-Q Method' for qPCR. Int J Biomed Sci 2008, 4:100-120

22. Gallup JM, Kawashima K, Lucero G, Ackermann MR: New quick method for isolating RNA from laser captured cells stained by immunofluorescent immunochemistry; RNA suitable for direct use in fluorogenic TaqMan one-step real-time RT-PCR. Biol Proced Online 2005, 7(1):70-92.

23. Kawashima K, Meyerholz DK, Gallup JM, Grubor B, Lazic T, Lehmkuhl HD, Ackermann MR: Differential expression of ovine innate immune genes by preterm and neonatal lung epithelia infected with respiratory syncytial virus. Viral Immunol 2006, 19:316-323.

doi:10.1186/1756-0500-7-158

Cite this article as: Grosz et al: Sucrose stabilization of Respiratory Syncytial Virus (RSV) during nebulization and experimental infection. BMC Research Notes 2014 7:158.

\section{Submit your next manuscript to BioMed Central and take full advantage of:}

- Convenient online submission

- Thorough peer review

- No space constraints or color figure charges

- Immediate publication on acceptance

- Inclusion in PubMed, CAS, Scopus and Google Scholar

- Research which is freely available for redistribution 